\title{
Strengthening of Reinforced Concrete T-Beams with externally bonded FRP Sheets to improve Shear Strength
}

\author{
Miss. Manjare Priyanka Balasaheb (Author) \\ M.E. Structures \\ SVERI's College of Engineering, Pandharpur \\ India
}

\author{
Prof. Mukund M. Pawar (Guide) \\ Department of Civil Engineering \\ SVERI's College of Engineering, Pandharpur \\ India
}

\author{
Prof. S. P. Patil \\ Department of Civil Engineering \\ SVERI's College of Engineering, Pandharpur \\ India
}

\begin{abstract}
The rehabilitation of existing reinforced concrete (RC) bridges and building becomes necessary due to ageing, corrosion of steel reinforcement, defects in construction/design, demand in the increased service loads, and damage in case of seismic events and improvement in the design guidelines. Fiberreinforced polymers (FRP) have emerged as promising material for rehabilitation of existing reinforced concrete structures. The rehabilitation of structures can be in the form of strengthening, repairing or retrofitting for seismic deficiencies. $\mathrm{RC} \mathrm{T}$-section is the most common shape of beams and girders in buildings and bridges. Shear failure of RC T-beams is identified as the most disastrous failure mode as it does not give any advance warning before failure. The shear strengthening of RC T-beams using externally bonded (EB) FRP composites has become a popular structural strengthening technique, due to the well-known advantages of FRP composites such as their high strength-toweight ratio and excellent corrosion resistance.

A few studies on shear strengthening of RC T-beams using externally bonded FRP sheets have been carried out but still the shear performance of FRP strengthened beams has not been fully understood. The present study therefore explores the prospect of strengthening structurally deficient T-beams by using an externally bonded fiber reinforced polymer (FRP).

This study assimilates the experimental works of glass fiber reinforced polymer (FRP) retrofitted RC T-beams under symmetrical four-point static loading system. The eight numbers of beams were of the following configurations, (i) one number of beams was considered as the control beam, (ii) seven number of the beams were strengthened with different configurations and orientations of FRP sheets.

The first beam, designated as control beam failed in shear. The failures of strengthened beams are initiated with the debonding failure of FRP sheets followed by brittle shear failure. However, the shear capacity of these beams has increased as compared to the control beam which can be further improved if the debonding failure is prevented. An innovative method of anchorage technique has been used to prevent these premature failures, which as a result ensure full utilization of the strength of FRP. A theoretical study has also been carried out to support few of the experimental findings.
\end{abstract}

Key words: Rehabilitation, FRP, debonding failure, structural strengthening

\section{INTRODUCTION}

Many old structures which were constructed using old codes and techniques are unable to withstand the latest technology and design methods and hence these old structures are required to be upgraded. Structures like buildings, girders, Bridge decks etc. are susceptible to damage due to age of structure, corrosion, adverse environments. After damages these structures are not capable to carry the load for which they have been designed.

Earthquakes are the most affecting natural disasters in buildings. So having knowledge of earthquakes is an important thing in the current era. This consideration demands revision in seismic loads on structure. The systemic effects have completely changed design methodology that's why older structures need retrofitting because replacing structures may lead to un-economical structure.

Most widely used techniques for retrofitting are steel jacketing and concrete jacketing. In concrete jacketing we Improve load carrying capacity by increasing cross sectional area. This may lead to Increased load due to increase the section, also it requires new formal words therefore it has high cost. Steel jacketing is the most effective technique but it requires difficult welding work on site, also it may have corrosion all this leads to increased maintenance cost.

All these things have led to more and more research work in this field. These researches have created a new milestone in modern Construction Techniques. One of the important outcomes of this research is Fiber reinforced polymer (FRP)

FRP composites comprise fibers of high tensile strength embedded within a thermosetting matrix such as epoxy, polymer or vinyl ester. The most widely used matrix is epoxy.

FRP was developed for using in aero planes spacecrafts Satellites helicopter Space shuttle etc. But later in 1980s it was started for using in civil structures. These where mainly used for rehabilitation of RCC structures. FRP's are having large advantages As follows:

1. FRP materials are not vulnerable to the swift electrochemical corrosion that occurs with steel

2. They can be easily rolled which makes transportation easy

3. High fatigue resistance

4. High strength to weight ratio 
5. Fiber composite materials are available in very long lengths while steel plate is generally limited to $6 \mathrm{~m}$. The availability of long length and the flexibility of the material simplify the installation process

6. Time required for installation is very less

7. Fiber composite strengthening materials have higher ultimate strength and lower density as compared to those of steel

8. Low energy consumption during fabrication of raw material and structure, and has the potential for real time monitoring

9. Tailor ability and ease of application

10. Excellent durability

Although FRP has many advantages it has one disadvantage that it is very sensitive to high growth thermal environment. FRPs are used in forms of bars, plates and sheets for strengthening RC beams. In these forms FRP sheets are commonly used due to their flexibility. As we know beam fails in flexure and shear. So FRP are needed in both zones for strengthening purpose. It may be classified as follows:

\section{A Flexural strengthening}

In this type FRPs installed on tension zone using an adhesive like epoxy. Its fibers are placed parallelly to the direction of tensile stress.

\section{B Shear strengthening}

Shear failure is one of the important types of failure in beams and it needs special consideration while designing. We can apply FRP to the beam for strengthening in shear in various ways. First by bonding FRP on the side of the beam. Secondly applying FRP in U shape including two side and bottom tension zones and thirdly we can a rap FRP on the whole cross section of beam. In T beams it is not feasible to use a third method. FRP has its highest strength only in the direction of fibres, these directions may be uni-directional, bidirectional or multi directional to achieve more benefit in shear we can use fibre in two directions.

In this project we will be using externally bonded FRP sheets for strengthening T-Beams in shear strength. FRPs will be applied in various shapes and at various locations on beam section. Later these beams will be tested using destructive test. Based on these test results analysis will be done that which will be suitable and most effective way of application of FRP.

\section{Objectives:}

The main objectives of the present work are:

1. To study the structural behavior of reinforced concrete (RC) T-beams under static loading condition.

2. To study the contribution of externally bonded (EB) Fiber Reinforced Polymer (FRP) sheets on the shear behavior of RC T-beams.

3. To examine the effect of different fiber orientations, number of layers etc. on the response of beam in terms of failure modes, enhancement of load carrying capacity and load deflection behavior.

4. To investigate the effect of a new anchorage scheme on the shear capacity of the beam.

5. To compare shear strength for $\mathrm{T}$-beam with or without FRP sheet.

\section{LITERATURE REVIEW}

The following critical observations are made from the review of existing literature:

- Many researchers are of the opinion that the previous design provisions do not have comprehensive understanding of the shear behaviour.

- There is a gain in shear capacity of RC beams when strengthened with FRP composites, peeling of FRP sheets from main concrete has been reported due to improper anchorage.

- Most of the research efforts have been made to study the flexural and shear behaviour of $\mathrm{RC}$ rectangular beams strengthened with fiber reinforced polymer (FRP) composites.

- A limited works have been reported on strengthening of RC T-beams with web openings.

- The study on anchorage system used for the prevention of debonding of FRP and concrete on shear behaviour of RC beams is limited.

- Despite the growing number of field applications, there is limited number of reports on shear behaviour of strengthened RC T-beams using externally bonded FRP composites.

\section{CASTING OF SPECIMEN}

Eight number of reinforced concrete T-beams are cast and tested up to failure by applying symmetrical four-point static loading system. Out of eight numbers of beams, one beam was not strengthened by FRP and was considered as a control beam, whereas all other seven beams were strengthened with externally bonded FRP sheets in shear zone of the beam. The variables investigated in this research study included FRP amount and distribution (i.e., continuous wrap versus strips), bonded surface (i.e., lateral sides versus U-wrap), FRP ratio (i.e., no. of layers), and end anchor (i.e., U-wrap with and without end anchor).

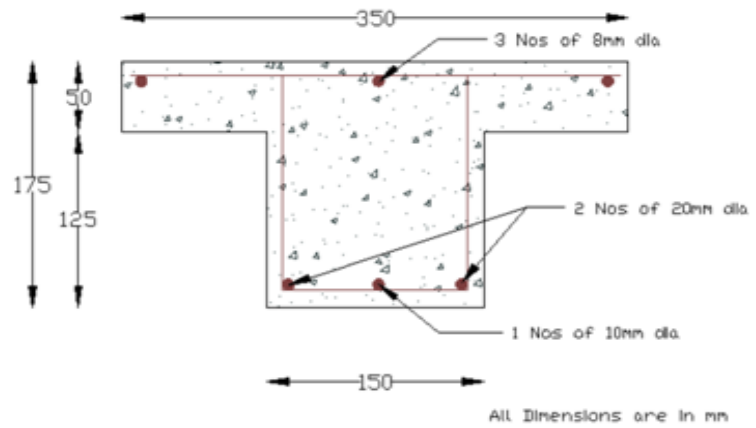

Detailing of Reinforcement

\section{A. Fiber Reinforced Polymer (FRP)}

Continuous fiber reinforced materials with polymeric matrix (FRP) can be considered as composite, heterogeneous, and anisotropic materials with a prevalent linear elastic behaviour up to failure. Normally, Glass and Carbon fibers are used as reinforcing material for FRP. Epoxy is used as the binding material between fiber layers. For this study, one type of FRP sheet was used during the tests i.e., a bidirectional FRP with the fiber oriented in both longitudinal and transverse directions, due to the flexible nature and ease of handling and application, the FRP sheets are used for shear strengthening. 
Throughout this study, E-glass was used manufactured by Owens Corning.

\section{B. Epoxy Resin}

The success of the strengthening technique primarily depends on the performance of the epoxy resin used for bonding of FRP to concrete surface. Numerous types of epoxy resins with a wide range of mechanical properties are commercially available in the market. These epoxy resins are generally available in two parts, a resin and a hardener. The resin and hardener used in this study are Araldite LY 556 and hardener HY 951 respectively.

\section{Fabrication of GFRP Plate for tensile strength}

There are two basic processes for moulding, that is, hand layup and spray-up. The hand lay-up process is the oldest, simplest, and most labour intense fabrication method. This process is the most common in FRP marine construction. In hand lay-up method liquid resin is placed along with reinforcement (woven glass fiber) against finished surface of an open mould. Chemical reactions in the resin harden the material to a strong, light weight product. The resin serves as the matrix for the reinforcing glass fibers, much as concrete acts as the matrix for steel reinforcing rods. The percentage of fiber and matrix was 50:50 in weight.

The following constituent materials are used for fabricating the GFRP plate:
i. Glass FRP (GFRP)
ii. Epoxy as resin
iii. Hardener as diamine (catalyst)

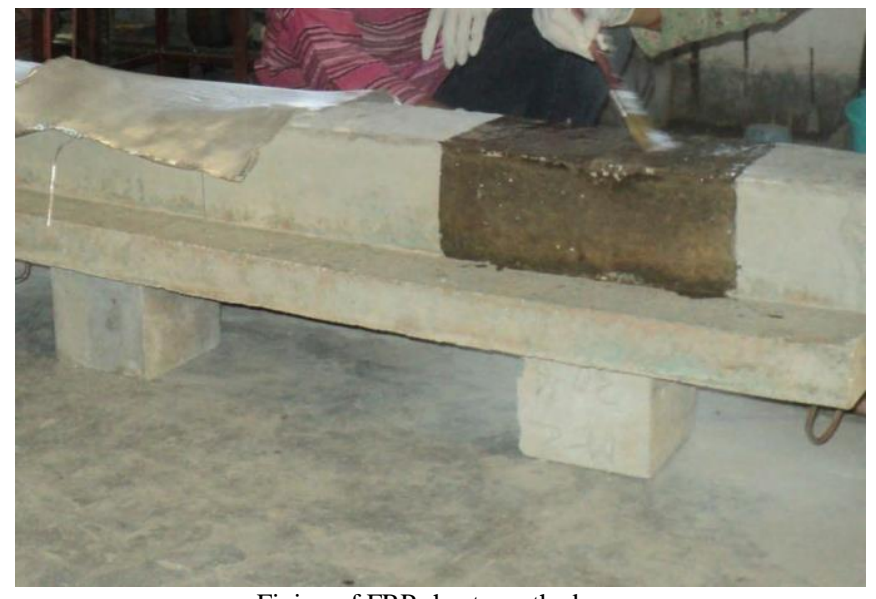

Fixing of FRP sheets on the beam

\section{iv. METHODOLOGY}

After casting and curing for 28 days all the specimens were tested as simply supported RC T-beams by using four-point static loading frame with shear span of effective depth ratio (a/d) as 2.38. A load cell of $500 \mathrm{kN}$ attached to hydraulic jack was used.

The load is transmitted through a load cell and spherical seating on to a spreader beam. This spreader beam is installed on rollers seated on steel plates bedded on the test member with cement in order to provide a smooth levelled surface. The test member is supported on roller bearings acting on similar spreader plates. The loading frame must be capable of carrying the expected test loads without significant distortion.
Ease of access to the middle third for crack observations, deflection readings and possibly strain measurements is an important consideration, as is safety when failure occurs. The specimen is placed over the two steel rollers bearing leaving $150 \mathrm{~mm}$ from the ends of the beam. The remaining $1000 \mathrm{~mm}$ is divided into three equal parts of $333 \mathrm{~mm}$ as shown in the figure. Load is applied by hydraulic jack of capacity $500 \mathrm{kN}$. Lines are marked on the beam to be tested at L/3, L/2, \& $2 \mathrm{~L} / 3$ locations from the left support $(\mathrm{L}=1300 \mathrm{~mm})$, three dial gauges are used for recording the deflection of the beams. One dial gauge is placed just below the centre of the beam, i.e. at L/2 distance and the remaining two dial gauges are placed just below the point loads, i.e. at $L / 3$ and $2 \mathrm{~L} / 3$ to measure the deflections.

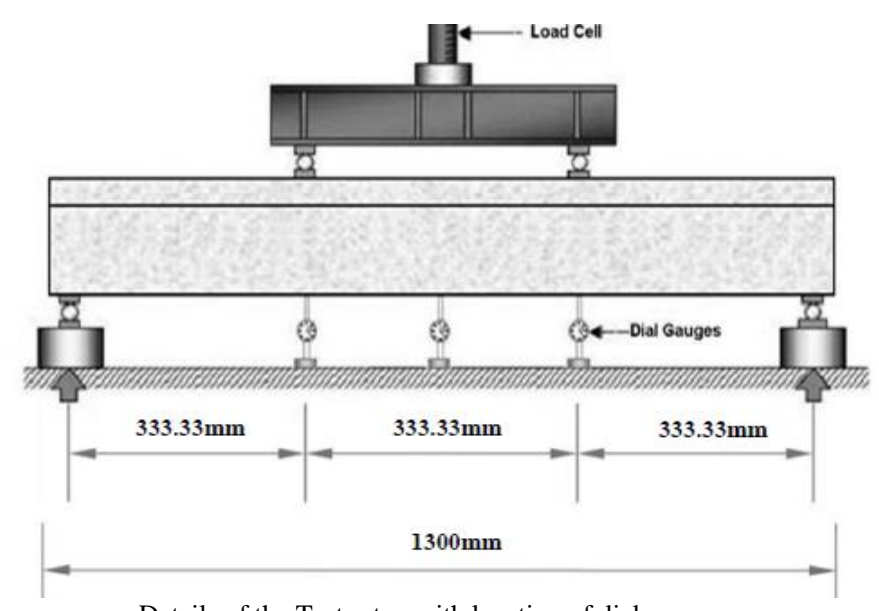

Details of the Test setup with location of dial gauges

\section{A. SPECIMEN DETAILS}

Eight specimens were considered as simply supported RC Tbeams. Reinforcement used for all specimens was two numbers of $20 \mathrm{~mm} \varphi$ and one number of $10 \mathrm{~mm} \varphi$.

\section{B. CONTROL BEAM (CB)}

This beam is not strengthened with FRP.

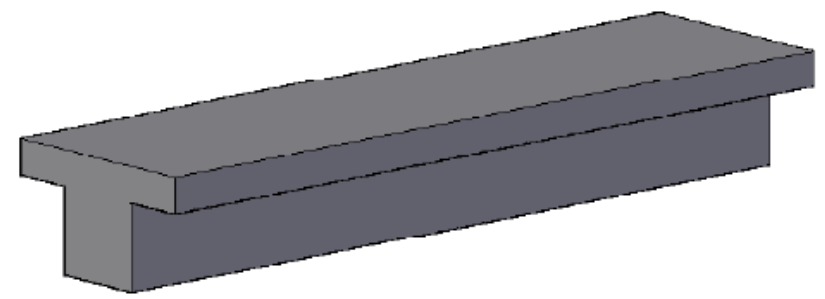

Model of T-beam without FRP - CB

\section{STRENGTHENED BEAM 1}

U-wrapped FRP on bottom and web portion with two layers at distance L/3 from both supports was used in this beam. 


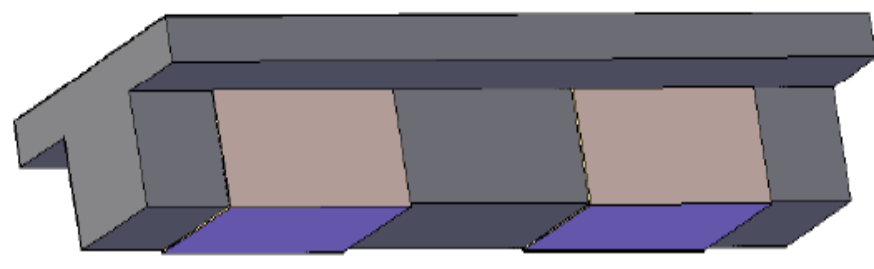

Model of T-beam with FRP - SB1

\section{STRENGTHENED BEAM 2}

Two layers of FRP on web portions on shear span at distance L/3 from both supports was used in this beam.

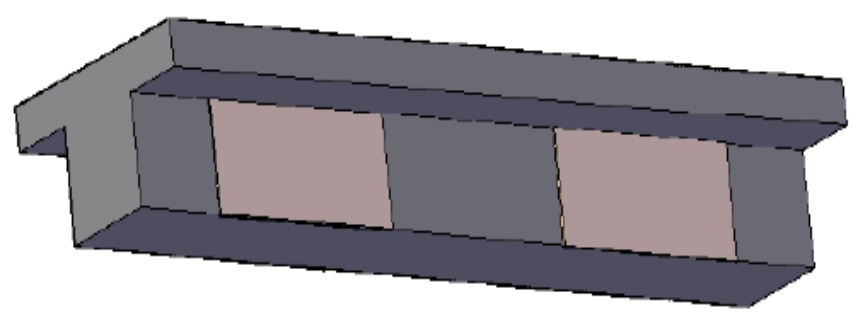

Model of T-beam with FRP - SB2

\section{E. STRENGTHENED BEAM 3}

Strengthened by applying two layers of GFRP U-strips on web portions and bottom on shear span at distance L/3 from both supports was used in this beam with three equal strips on both sides of the beam, each strip of size thickness as $50 \mathrm{~mm}$ and the spacing between the strips is $50 \mathrm{~mm}$.

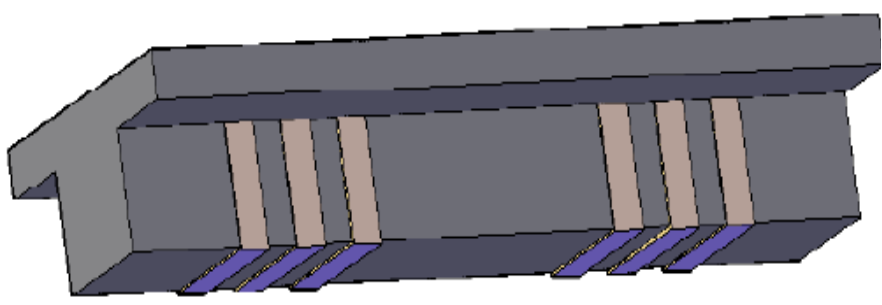

Model of T-beam with FRP - SB3

\section{F. STRENGTHENED BEAM 4}

The beam (SB4) was strengthened by applying two layers of FRP strips only on web portions on shear span at distance L/3 from both supports with three equal strips on both sides of the beam.

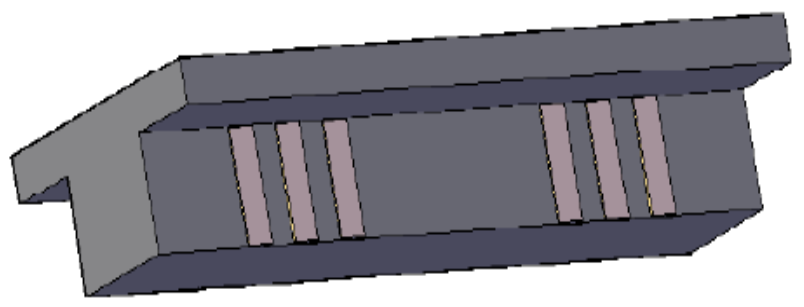

Model of T-beam with FRP - SB4

\section{G. STRENGTHENED BEAM 5}

The beam (SB5) was strengthened by applying two layers of FRP strips only onsides of web portions on shear span region (distance L/3 from both supports) with two equal strips on both sides of the beam which is inclined to 450 as shown in figure, each strip of size thickness as $50 \mathrm{~mm}$ and the spacing between the strips is $50 \mathrm{~mm}$.

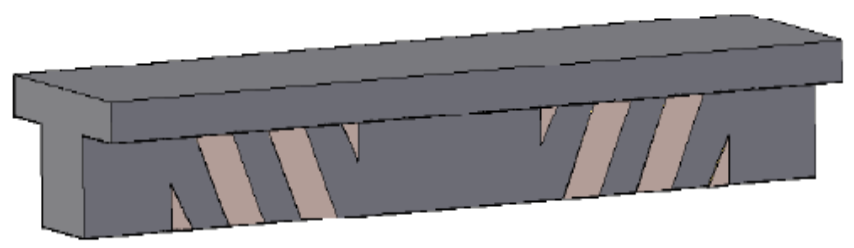

Model of T-beam with FRP - SB5

\section{H. STRENGTHENED BEAM 6}

The beam is modeled with two layers of FRP having U-wrap on bottom and web portions on the shear span (distance L/3 from both supports) of the beam. It is found that in most cases debonding happens between the glass-fiber and the concrete. To reduce the debonding effect steel plates are used and tightened with bolts i.e., the anchorage system

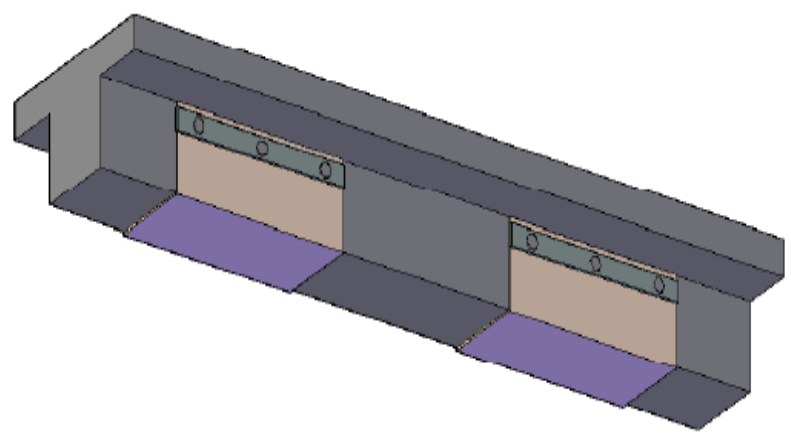

Model of T-beam with FRP - SB6

\section{STRENGTHENED BEAM 7}

The beam is modelled with four layers of FRP having U-wrap on bottom and web portions on the shear span (at distance L/3 from both supports) of the beam. Here, also to reduce the debonding effect steel plates are used and tightened with bolts.

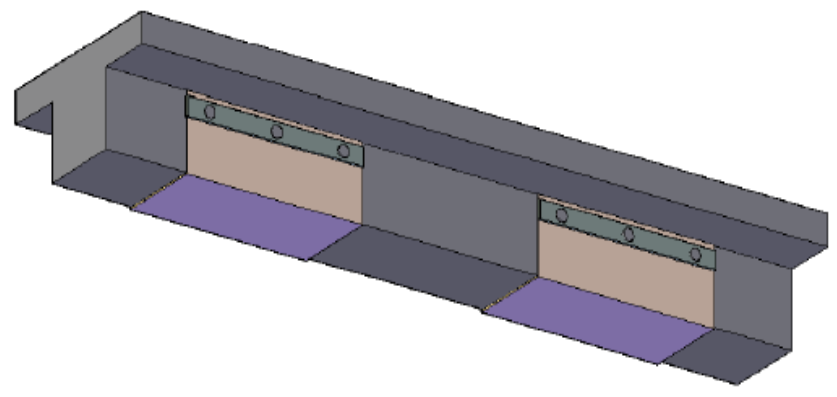

Model of T-beam with GFRP - SB7 
v. RESULTS

Table 8 Ultimate load and nature of failure for various beams

\begin{tabular}{|c|c|c|c|}
\hline $\begin{array}{c}\text { Beam } \\
\text { Designation }\end{array}$ & $\begin{array}{l}\text { Nature of } \\
\text { Failure }\end{array}$ & $\begin{array}{c}\mathbf{P u} \\
(\mathbf{k N})\end{array}$ & $\begin{array}{c}\lambda=\frac{\mathrm{Pu}(\text { strengthened }}{\text { beam) }} \\
\mathrm{Pu(control} \mathrm{beam)}\end{array}$ \\
\hline $\mathrm{CB}$ & Shear failure & 168 & - \\
\hline SB 1 & $\begin{array}{l}\text { Debonding of } \\
\text { FRP with } \\
\text { concrete crushing } \\
\text { + Shear failure }\end{array}$ & 249 & 1.48 \\
\hline SB 2 & $\begin{array}{l}\text { Debonding of } \\
\text { FRP with } \\
\text { concrete cover }+ \\
\text { Shear failure }\end{array}$ & 207 & 1.23 \\
\hline SB 3 & $\begin{array}{c}\text { Tearing and } \\
\text { Debonding of } \\
\text { FRP without } \\
\text { concrete cover + } \\
\text { Shear failure }\end{array}$ & 224 & 1.33 \\
\hline SB 4 & $\begin{array}{c}\text { Tearing and } \\
\text { Debonding of } \\
\text { FRP without } \\
\text { concrete cover + } \\
\text { Shear failure }\end{array}$ & 177 & 1.05 \\
\hline SB 5 & $\begin{array}{c}\text { Tearing of FRP + } \\
\text { Shear failure }\end{array}$ & 225 & 1.34 \\
\hline SB 6 & $\begin{array}{l}\text { Tearing of FRP + } \\
\text { Shear failure }\end{array}$ & 264 & 1.57 \\
\hline SB 9 & $\begin{array}{c}\text { Tearing of FRP + } \\
\text { Shear failure }\end{array}$ & 277 & 1.65 \\
\hline
\end{tabular}

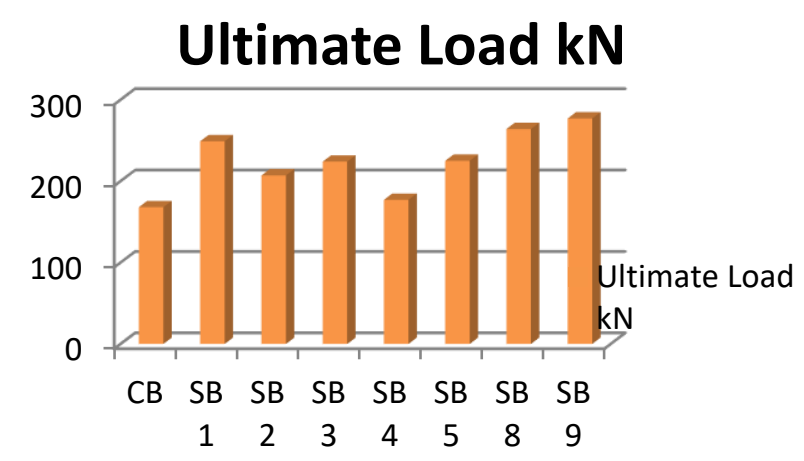

Graph 1: Ultimate load carried by beams

\section{A. DEFLECTION OF BEAM}

Deflection for all eight beams was recorded at location under loading point and at mid span. Load vs deflection curve for various beams are as follows:

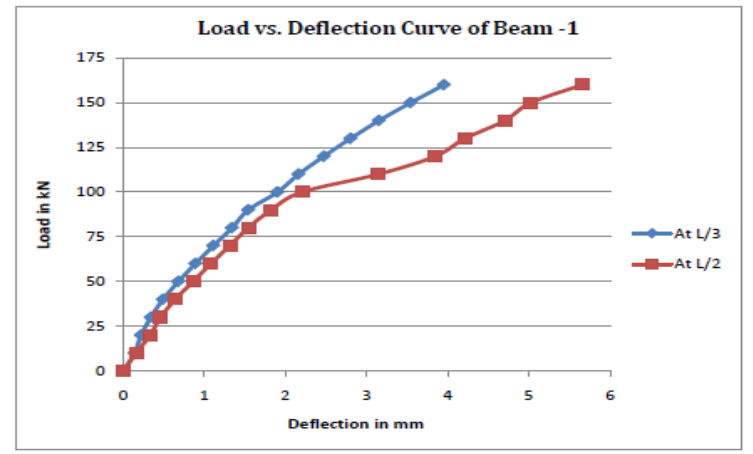

Graph 2: Load vs. Deflection Curve for CB

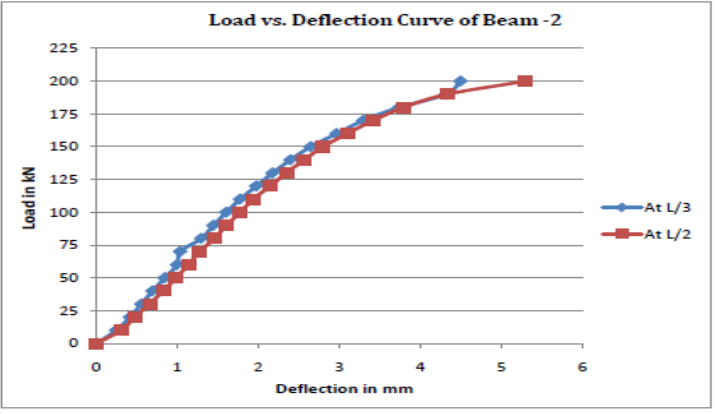

Graph 3: Load vs. Deflection Curve for SB1

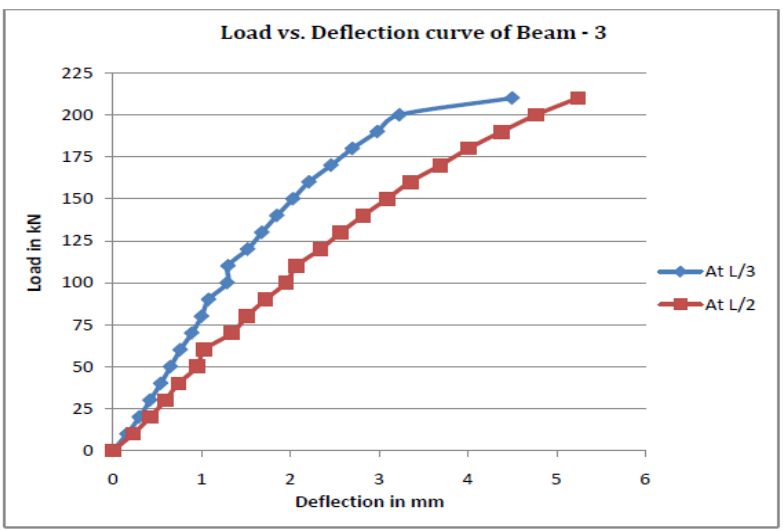

Graph 4: Load vs. Deflection Curve for SB2

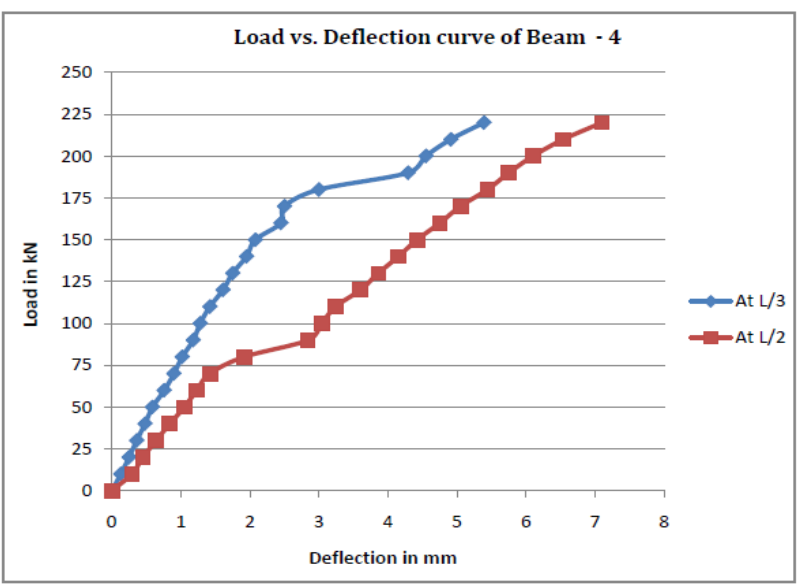

Graph 5: Load vs. Deflection Curve for SB3

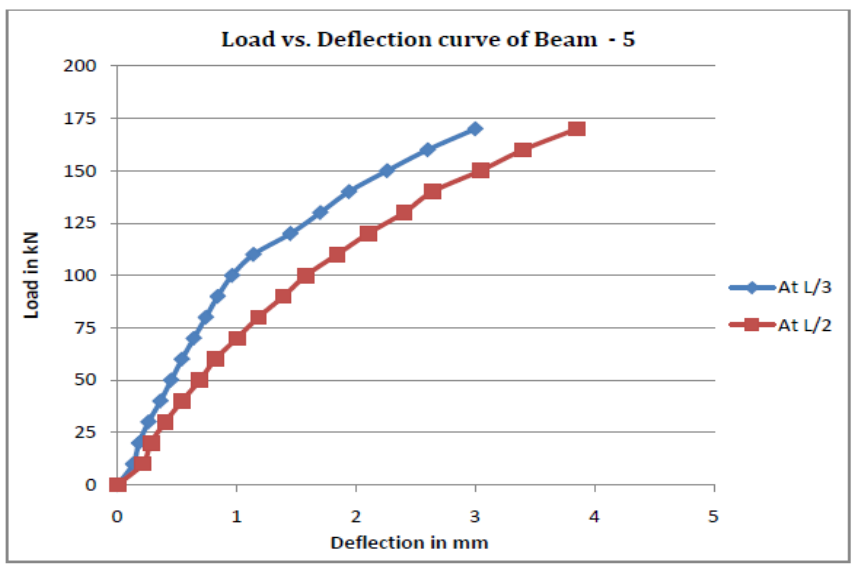

Graph 6: Load vs. Deflection Curve for SB4 

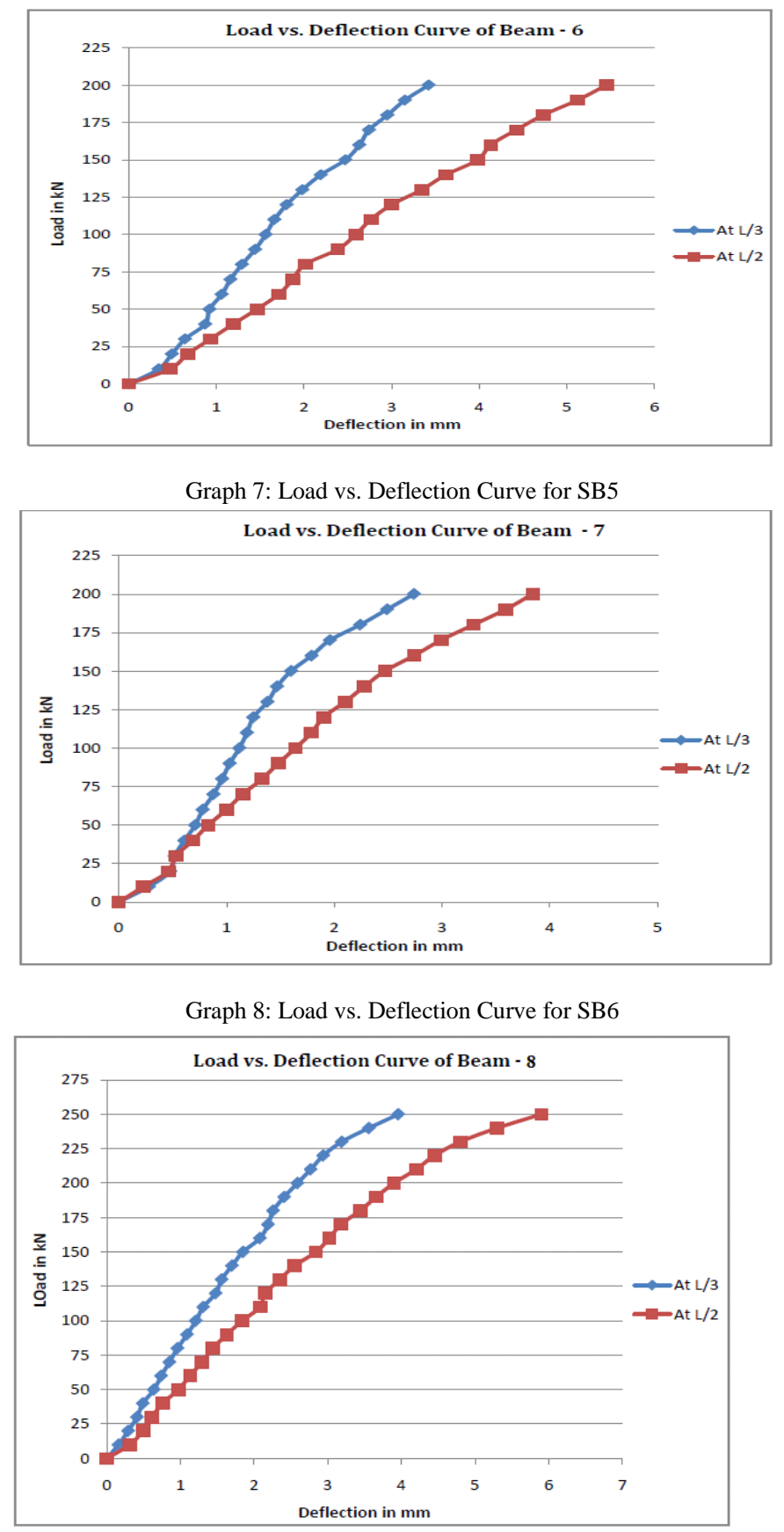

Graph 9: Load vs. Deflection Curve for SB7

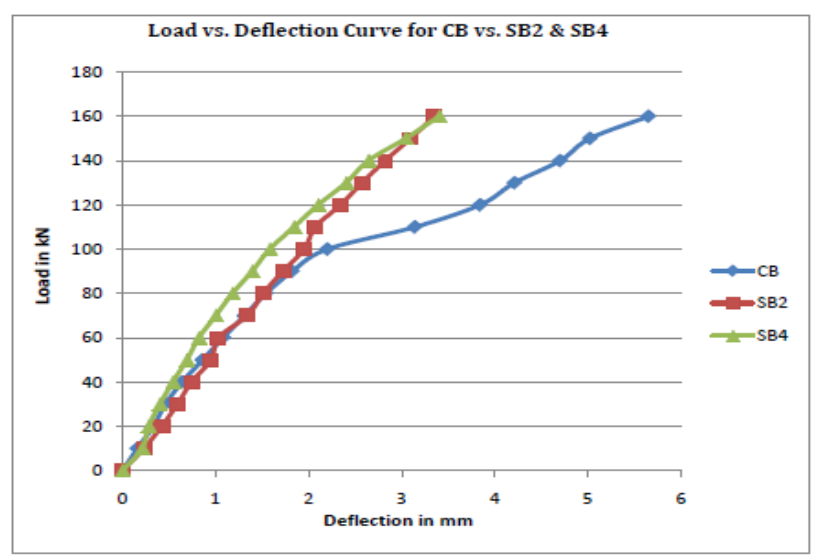

Graph 10: Loads vs. Deflection Curve for CB vs. SB2 and SB4
From above curve we can observe that SB2 and SB4 behave similarly in terms of deflection. Again CS shows more deflection as compared to SB2 and SB4.

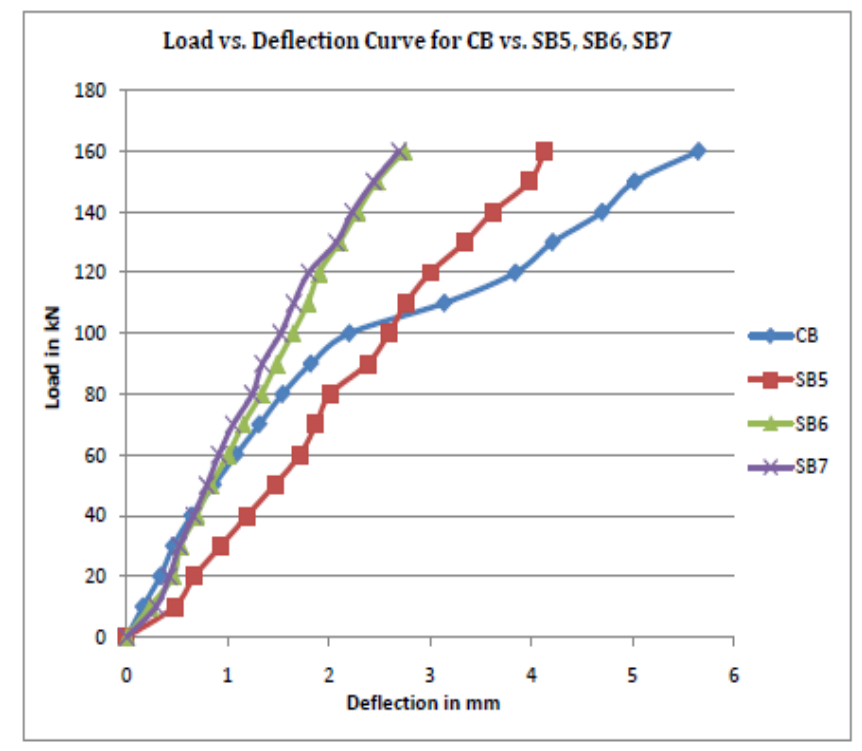

Graph 11: Load vs. Deflection Curve for CB vs. SB5, SB6 and SB7

Similarly this curve shows comparison of deflection for $\mathrm{CB}$, SB5, SB6 and SB7. From above graphs it is clearly visible that strengthened beams shows less deflection as compared to controlled beam.

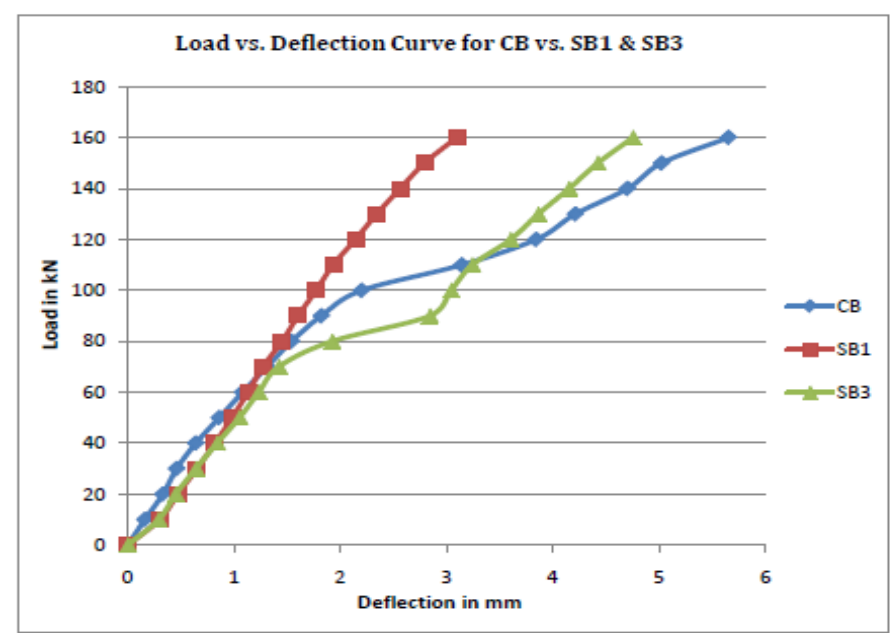

Graph 12: Loads vs. Deflection Curve for CB vs. SB1 and SB3

SB1 shows less deflection compared to $\mathrm{CB}$ and SB3 at higher load. Above graph shows comparison of mid span deflection for beams CB, SB1 and SB3. It is clearly visible that FRP can help in controlling deflection for some extent.

\section{vi. THEORETICAL STUDY}

The layout technique is expressed in American Concrete Institute (ACI) design code format. The main elements affecting the additional power that can be carried out with the aid of the externally bonded FRP reinforcement had been considered. The experimental version described two viable failure mechanisms of FRP 
reinforcement together with FRP debonding and FRP rupture. The shear energy of Reinforced Concrete (RC) T-beams are theoretically computed for varying diploma of FRP strengthening.

A. Factors affecting the shear contribution of FRP

Experimental results showed the following factors that have affected shear contribution of FRP:

- Wrapping schemes (U-wrap or fiber attached on the two web sides of the beam).

- Presence of FRP end anchor.

- Fiber orientation.

- Concrete surface preparation and surface roughness.

- Amount and distribution of FRP reinforcement.

\section{B. Design of Material Properties}

Following are the equations that are needed to be considered to calculate properties that should be used in all design equations:

\section{Design ultimate tensile strength $=f_{\mathbf{f u}}=\mathbf{C}_{\mathbf{E}} f_{\text {fum }}$}

where,

$$
\begin{aligned}
& f_{\mathrm{fu}}=\text { design ultimate tensile strength of } \\
& \text { FRP, }\left(\mathrm{N} / \mathrm{mm}^{2}\right) \\
& C_{\mathrm{E}}=\text { environmental reduction factor } \\
& f_{\text {fum }}=\text { ultimate tensile strength of the FRP } \\
& \text { materials as reported by the } \\
& \quad \text { manufacturer, }\left(\mathrm{N} / \mathrm{mm}^{2}\right)
\end{aligned}
$$

\section{Design rupture strain $=\varepsilon_{\mathrm{fu}}=\mathrm{C}_{\mathrm{E}} \varepsilon^{*} \mathrm{fu}$}

Where,

$$
\begin{aligned}
& \varepsilon_{f u}=\text { design rupture strain of FRP } \\
& \text { reinforcement, }(\mathrm{mm} / \mathrm{mm}) \\
& \varepsilon_{f u}^{*}=\text { ultimate rupture strain of the FRP } \\
& \text { reinforcement, }(\mathrm{mm} / \mathrm{mm})
\end{aligned}
$$

Design modulus of Elasticity $E_{f}=\frac{f_{f u}}{\varepsilon_{f u}}$

The material used for this present work is glass fiber and epoxy resin, and the exposure condition is internal exposure. For present calculation the environmental reduction factor $(\mathrm{CE})$ is used as 0.75

\section{Nominal Shear Strength:}

For normal beam:

$$
V_{n}=V_{c}+V_{s}
$$

Where,

$$
\begin{aligned}
& V_{n}=\text { Nominal shear strength. } \\
& V_{c}=\text { shear strength of concrete. } \\
& V_{s}=\text { shear strength of steel. }
\end{aligned}
$$

For beam strengthened with FRP:

$$
V_{n}=V_{c}+V_{s}+V_{f}
$$

Where,

$$
\begin{aligned}
& \mathrm{V}_{\mathrm{n}}=\text { Nominal shear strength. } \\
& \mathrm{V}_{\mathrm{c}}=\text { shear strength of concrete. } \\
& \mathrm{V}_{\mathrm{s}}=\text { shear strength of steel. } \\
& \mathrm{V}_{\mathrm{f}}=\text { shear strength of FRP }
\end{aligned}
$$

\section{Design Shear Strength:}

The basic design equation for the shear capacity of a concrete member is;

$$
V_{u} \leq \phi V_{n}
$$

Where,

$$
\begin{aligned}
& \mathrm{V}_{\mathrm{u}}=\text { design shear strength. } \\
& \phi=\text { reduction factor }=0.85 \text { for concrete } \\
& \text { and steel } \\
& \mathrm{V}_{\mathrm{n}}=\text { Nominal shear strength. }
\end{aligned}
$$

$\mathrm{Vu}$ is the total shear force applied at a given section due to the factored loads.

The nominal shear strength of an FRP-strengthened concrete member can be determined by adding the contribution of the FRP reinforcing to the contributions from the reinforcing steel (stirrups, ties, or spirals) and the concrete. An additional reduction factor $\psi \mathrm{f}$ is applied to the contribution of the FRP system.

$$
\phi V_{n}=\phi\left(V_{c}+V_{s}+\psi_{f} V_{f}\right)
$$

It is suggested that an additional reduction factor $\psi \mathrm{f}$ be applied to the shear contribution of the FRP reinforcement. For bondcritical shear reinforcement, an additional reduction factor of 0.85 (Completely wrapped members) is recommended. For contact-critical shear reinforcement, an additional reduction factor of 0.95 (Three-sided U-wraps or bonded face piles) is recommended in code ACI 440.2R-02.

E. FRP system contribution to shear strength
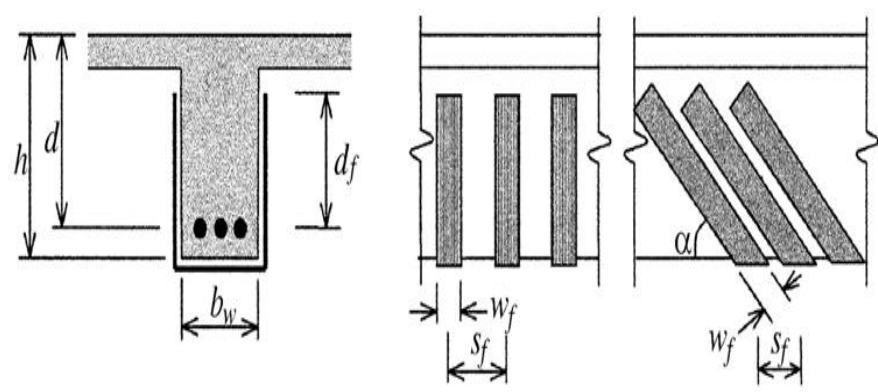

Illustration of the dimensional variables used in shear- 


\section{strengthening calculations for repair, retrofit, or}

\section{strengthening using FRP laminates.}

The contribution of the FRP system to shear strength of a member is based on the fiber orientation and an assumed crack pattern [Khalifa et al. 1998]. The shear strength provided by the FRP reinforcement can be determined by calculating the force resulting from the tensile stress in the FRP across the assumed crack.

$$
\mathbf{V}_{f}=\frac{A_{f v} f_{f e}(\sin \propto+\cos \propto) d_{f}}{s_{f}}
$$

Where,

$\mathrm{A}_{f v}=$ area of one strip of transverse FRP reinforcement covering two sides of the beam.

$$
\mathbf{A}_{f v}=2 t_{f} w_{f}
$$

$\mathrm{t}_{f}=$ thickness of FRP provided

$\mathrm{w}_{f}=$ width of FRP provided

$\mathrm{s}_{f}=$ distance from the centerline of one strip to the centerline of an adjacent strip (spacing)

$\propto=$ angle between principal fiber orientation and longitudinal axis of the beam

$$
\begin{array}{r}
f_{f e}=\text { tensile stress in the FRP } \\
\qquad \boldsymbol{f}_{\boldsymbol{f} e}=\boldsymbol{\varepsilon}_{f e} \boldsymbol{E}_{f}
\end{array}
$$

F. Effective strain in FRP laminates

All possible failure modes should be considered and the effective strain should be used which is the representative of the critical failure mode. Maximum strain that can be achieved in the FRP system at the ultimate load stage is called as effective strain and it is governed by the failure mode of the FRP system and the strengthened reinforced concrete member.

\section{Completely wrapped members:}

Loss of aggregate interlock of the concrete has been observed to occur at fiber strains less than the ultimate fiber strain. $0.4 \%$ of maximum strain used for design for applications that can be completely wrapped with the FRP system, to avoid such kind of failure.

$$
\varepsilon_{f e}=0.004 \leq 0.75 \varepsilon_{f u}
$$

Higher strains should not be used for FRP shear-strengthening applications. This strain limitation is based on testing [Priestley et al. 1996] and experience.

Bonded U-wraps or bonded face plies:

$$
\varepsilon_{f e}=k_{v} \varepsilon_{f u} \leq 0.004
$$

$\mathrm{k}_{\mathrm{v}}=$ bond-reduction coefficient for shear.

$$
\mathrm{K}_{2}=\left\{\begin{array}{l}
\frac{d_{f}-L_{e}}{d_{f}} \\
\frac{d_{f}-2 L_{e}}{d_{f}}
\end{array}\right.
$$

for $\mathrm{U}$ - wraps

for two side bonded

G. Reduction coefficient based on Rupture failure mode

$$
\begin{aligned}
& \text { For } \rho_{f} E_{f} \leq 0.7: \\
& \qquad R=0.5622\left(\rho_{f} E_{f}\right)^{2}-1.218\left(\rho_{f} E_{f}\right)+0.778
\end{aligned}
$$

where,

$$
\begin{aligned}
& \rho_{f}=\text { FRP shear reinforcement ratio }\left(2 t_{f} / b_{w}\right) \\
& \left(w_{f} / s_{f}\right) \\
& E_{f}=\text { tensile modulus of elasticity of FRP. }
\end{aligned}
$$

H. Reduction coefficient based on Debonding failure mode

The bond-reduction coefficient is a function of the concrete strength, the type of wrapping scheme used, and the stiffness of the laminate. The reduction coefficient based on debonding failure mode, is given in ACI 440.2R-02 design approach. kv is used as bond reduction coefficient.

$$
k_{v}=\frac{k_{1} k_{2} L_{e}}{11,900 \epsilon_{f u}} \leq 0.75
$$

Where,

Le $=$ active bond length i.e the length over which the majority of the bond stress is maintained.

$$
=\frac{23,300}{\left(n t_{f} E_{f}\right)^{0.58}}
$$

$\mathrm{K}_{1}=\left(\frac{f_{c^{\prime}}}{27}\right)^{\frac{2}{3}}$

$f_{c}$ ' $=$ concrete strength in MPa.

$\mathrm{E}_{f}=$ tensile modulus of elasticity of FRP in

$\mathrm{MPa}$.

Comparison of shear contribution of GFRP sheet from experimental and ACI Guidelines

\begin{tabular}{|c|c|c|c|}
\hline \multirow{3}{*}{ Specimen } & Experimental Results & \multicolumn{2}{|c|}{ Results as per ACI Guideline } \\
\cline { 2 - 4 } & $\begin{array}{c}\text { Vf,test } \\
(\boldsymbol{k N})\end{array}$ & $\begin{array}{c}\boldsymbol{V} \text { Vf,theor } \\
(\boldsymbol{k N})\end{array}$ & $\begin{array}{c}\text { Vf,test/Vf, } \\
\text { theor }\end{array}$ \\
\hline CB & - & - & - \\
\hline SB1 & 40.5 & 7.646 & 5.29 \\
\hline SB2 & 19.5 & 7.646 & 4.19 \\
\hline SB3 & 28 & 7.646 & 3.66 \\
\hline SB4 & 4.5 & 7.646 & 0.58 \\
\hline SB5 & 28.5 & 10.814 & 2.63 \\
\hline SB6 & 48 & 7.646 & 6.27 \\
\hline SB7 & 54.5 & 36.95 & 1.47 \\
\hline
\end{tabular}

Where, 
It is found from the Table that the ratio of Vf,test to Vf,theor is the highest for the beam SB6 strengthened with continuous FRP U-wrap with end anchorage and lowest for the beam SB4 strengthened with side vertical strips.

\section{vii. CONCLUSION}

This project included the study of RC T-beams strengthened with FRP. Result showed that strengthened beams with FRP can improve deficiency in shear strength of RC T- beams. This depends on fiber wrapping, orientations, number of layers and anchorage scheme.

Following are the conclusions that can be drawn from this project:

1. FRP can improve the shear strength of RC T-beams.

2. As per test, beams strengthened with FRP shows initial cracks at higher load.

3. Strengthening of on the webs with FRP is most vulnerable to debonding with premature failure.

4. The beam strengthened with a U-wrap configuration is more effective than the side-wrap configuration.

5. The use of anchorage system eliminates the debonding of the FRP sheet, and consequently results in a better utilization of the full capacity of the FRP sheet.

6. Applying FRP to the beam with end anchorage is better than strengthening without end anchorage.

7. Strengthened beam has high load carrying capacity than the control beam.

8. T-beam strengthened with U-wrap has more shear strength than that of the beam without openings.

9. From this study we can recommend the use of FRP sheets as an external reinforcement in order to increase the shear strength of T-beams with anchorage system.

\section{REFERENCES}

1) $\mathrm{ACI}$ 440.2R-02, "Guide for the Design and Construction of Externally Bonded FRP Systems for Strengthening Concrete Structures", Reported by ACI Committee 440.

2) Alex L., Assih J., and Delmas Y. (2001), "Shear Strengthening of RC Beams with externally bonded CFRP sheets", Journal of Structural Engineering, Vol. 127, No. 4, Paper No. 20516.

3) Balamuralikrishnan R., and Jeyasehar C. A. (2009), "Flexural behaviour of RC beams strengthened with Carbon Fiber Reinforced Polymer (CFRP) fabrics", The Open Civil Engineering Journal, 3, 102-109.

4) Deifalla A., and Ghobarah A. (2010), "Strengthening RC T beams subjected combined torsion and shear using FRP fabrics: Experimental Study", Journal of Composites for Construction, ASCE, pp. 301-311.

5) Duthinh D. and Starnes M. (2001), "Strengthening of RC beams with CFRP: Experimental results versus prediction of codes of practice", Journal of Composites for Construction, 16,185-195.

6) Ghazi J. Al-Sulaimani, Alfarabi Sharif, Istem A. Basunbul, Mohhamed H. Baluch, and Bader N. Ghaleb (1994), "Shear Repair for Reinforced Concrete by Fiberglass Plate Bonding", ACI Structural Journal, Vol. 91, Issue No. 4, pp. 458-464.

7) Hadi M. N. S. (2003), "Retrofitting of shear failed reinforced concrete beams", Composite Structures, 62, 1-6.

8) Khalifa A, Gold WJ, Nanni A and Aziz A. (1998), "Contribution of externally bonded FRP to shear capacity of RC flexural members", Journal of Composites for Construction, 2, 195-201.

9) Khalifa A., Lorenzis L. D., and Nanni A. (2000), "FRP composites for shear strengthening of RC beams", Proceedings, 3rd
International Conference on Advanced Composite Materials in Bridges and Structures, 15-18 Aug., pp. 137-144.

10) Khalifa A., and Nanni A. (2000), "Improving shear capacity of existing RC T-section beams using CFRP composites", Cement \& Concrete Composites, 22, 165-174. 